\title{
Intestinal Ischemia Due to Mesenteric Vascular Thrombosis in a Patient with Positive SARS-Cov-2 RNA without Primary Pulmonary Symptom: A Case Report
}

\author{
Akram Asghari ${ }^{~}$, Seyed Hasan Adeli ${ }^{1}$, Jamshid Vafaeimanesh ${ }^{1,2, *}$, Hamed Bagheri ${ }^{1}$, \\ Mohammad Riahi ${ }^{1}$, Mahsa Mirdamadi ${ }^{3}$
}

ABSTRACT

1. Clinical Research Development Center, Qom University of Medical Sciences, Qom, Iran

2. Gastroenterology and Hepatology Disease Research Center, Qom University of Medical Sciences, Qom, Iran

3. Rajaie Cardiovascular Medical and Research Center, Iran University of Medical Sciences, Tehran, Iran

\footnotetext{
* Corresponding Author:
}

Jamshid Vafaeimanesh, MD

Gastroenterology and Hepatology Disease Research Center, Shahid Beheshti Hospital, Shahid Beheshti Boulevard, Qom

Tel: + 982536122949

Fax: + 982536122945

Email: jvafaeemaneah@yahoo.com

Received: 16 Aug. 2020

Accepted: 07 Dec. 2020
Coronavirus disease 2019 (COVID-19) is an acute respiratory illness caused by novel coronavirus SARS-CoV-2. The clinical manifestations of this infection have a range and typically include impairment of smell, taste disturbance, cough, fever, and shortness of breath. Gastrointestinal manifestations have been reported in anywhere from $3 \%$ to $50 \%$ of patients with concomitant SARS-CoV-2 pulmonary infection. Abnormalities in coagulation markers have been reported in patients hospitalized with COVID-19. During this article, we will introduce a patient with COVID 19 but with the most manifestation of abdominal pain due to intestinal ischemia and mesenteric vascular thrombosis.

\section{KEYWORDS:}

Coronavirus disease 2019 (COVID-19), Intestinal ischemia, Acute mesenteric ischemia

\author{
Please cite this paper as: \\ Asghari A, Adeli SH, Vafaeimanesh J, Bagheri H, Riahi M, Mirdamadi M. Intestinal \\ Ischemia Due to Mesenteric Vascular Thrombosis in a Patient with Positive SARS- \\ Cov-2 RNA without Primary Pulmonary Symptom: A Case Report. Middle East J Dig \\ Dis 2021;13:75-79. doi: 10.34172/mejdd.2021.208.
}

INTRODUCTION

Coronavirus disease 2019 (COVID-19) is an acute respiratory illness caused by novel coronavirus SARS-CoV-2. This enveloped virus has positive-sense RNA and belongs to the Coronaviridae family. On 12 January 2020, the World Health Organization (WHO) named this new virus the "2019-novel coronavirus" (2019-nCoV). ${ }^{1}$ The primary cases in Iran were reported in Qom in February 2020, and shortly, positive cases increased rapidly everywhere in Iran. ${ }^{2}$ The clinical manifestations of this infection have a good range and typically include impairment of smell, taste disturbance, cough, fever, and shortness of breath. ${ }^{3}$ There has been a growing appreciation of the importance of digestive symptoms (nausea, vomiting, anorexia, non-bloody diarrhea, and abdominal pain) within the spectrum of COVID-19 disease. Also, abnormalities in coagulation markers have been reported in patients hospitalized with COVID- $19 .{ }^{4} \mathrm{Co}-$ agulopathy is one of the foremost significant prognostic factors in patients with COVID-19 and is related to increased mortality and admission to critical care. ${ }^{5}$ In severe cases of COVID-19, SARS-CoV-2 induces a cytokine storm that ultimately leads to impaired pulmonary gas exchange and acti- 


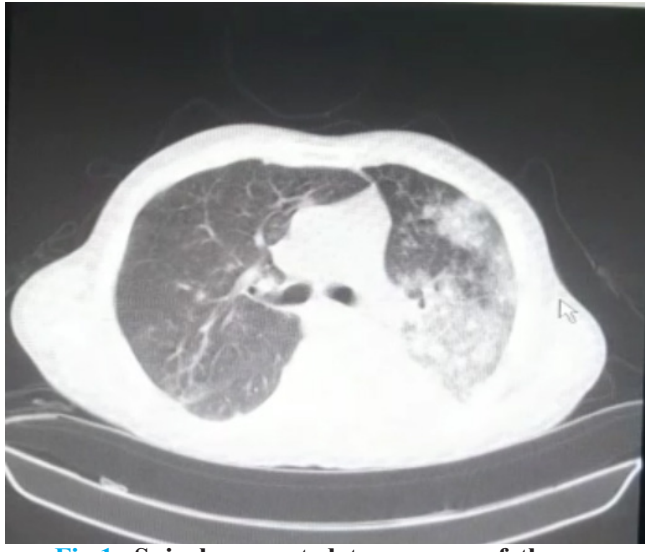

Fig.1: Spiral computed tomogram of the lung (without contrast).

vation of the coagulation cascade, causing thrombotic manifestations ${ }^{6}$ and median plasma concentrations of tissue factor and plasminogen activator inhibitor-1 (PAI-1) reported to be significantly higher in patients withAcute respiratory distress syndrome (ARDS) (at 7 days) compared with patients without ARDS (data not from COVID-19 patients). ${ }^{7}$ These and other changes increase coagulation status in patients with COVID 19.

The current concept of hypercoagulative states is supported by autopsies that have demonstrated small fibrinous thrombi in small pulmonary arterioles in areas of both damaged and more preserved lung parenchyma in 8 out of 10 cases. $^{8}$ Furthermore,the indication of coagulation activation due to infection/sepsis is cytokine storm, and imminent organ failure. ${ }^{9}$

In this article, we will introduce a patient who suffered from intestinal ischemia due to COVID 19 caused by acute mesenteric ischemia and had presented with abdominal pain and no initial pulmonary symptoms. To our knowledge, this is the first patient to be identified with this manifestation of COVID 19.

\section{CASE REPORT}

A 51-year-old male non-smoker was referred to the emergency room (ER) with the complaint of abdominal pain 3 days earlier,which she rated an " 8 " on a scale of 1 to 10 without any medical history and drug history. He stated that the pain worsened

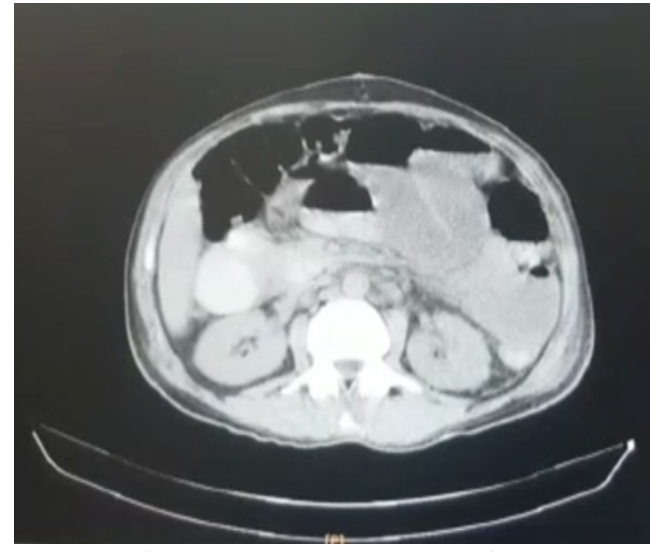

Fig.2: Spiral computed tomogram of abdominopelvic (without contrast). Evidence of dilation in small bowel loops filled by fluid suggests an obstructive syndrome or ileus.

with movement and change in position. He denied any significant family history of the disease. During the physical examination, the patient was diaphoretic, uncomfortable, and in severe distress. His vital signs were: blood pressure, 156/87 mm Hg; respiratory rate, 19 breaths/minute; heart rate, 132 beats/minute; and temperature within normal limits. Oxygen saturation was $93 \%$ on room air. The abdominal examination revealed a distended abdomen that was severely tender to palpation. Intravenous (IV) fluids were immediately started for the patient. He was also given IV ondansetron for nausea. His pain was refractory to treatment and required multiple doses of morphine sulfate. Laboratory evaluation revealed leukocytosis with a white blood cell (WBC) count of 14.5 thou/cm. He underwent laparotomy due to tenderness in favor of acute abdominal pain. During laparotomy, not only the small and large intestine but also their vasculature was normal. After two days, the patient was discharged with no pain and symptom. With nausea, abdominal pain, and dyspnea, he came back to the ER again after 3 days. On examination, he had tachypnea (RR: 40/ min), tachycardia (HR: 120/min), low-grade fever (Temp: $38^{\circ}$ centigrade). A lung computed tomography (CT) (Figure 1) and an abdominopelvic CT (Figure 2) were done. The patient was intubated due to respiratory failure. Covid-19 RT-PCR (Everse transcription polymerase chain reaction) was performed. Lab data included complete blood count 


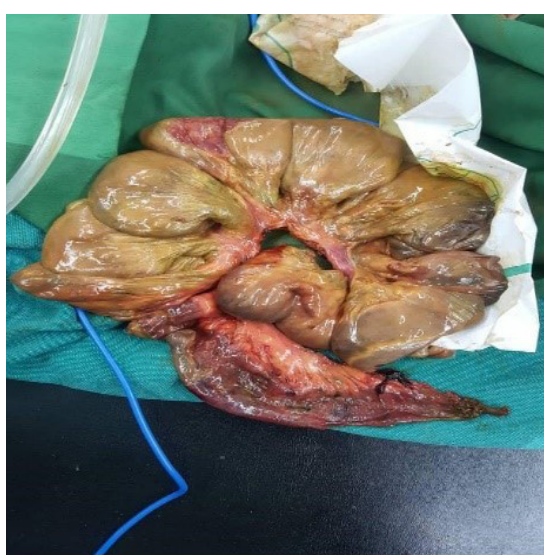

Section of the perforated site and necrotic areas show extensive mucosal infarction and fullthickness necrosis. Fibrin thrombi present in a few small to medium-sized vessels in these areas.

Fig.3: Gross and microscopic view of the small intestine. Perforated and gangrenous small bowel.

(CBC)(WBC:17000 per microliter, Hb:12:8.7 g/ dL, Plt: 350,000 per microliter), urea :170 mg/dL, (creatinine) Cr: $4.2 \mathrm{mg} / \mathrm{dL}$, (Lactate dehydrogenase) LDH:504 U/L, (C-reactive protein) CRP:47mg/L, and negative viral disease (HCV Ab-hepatitis $\mathrm{C}$ virus antibody, HBS Ag-Hepatitis B Antigen,, HIV $\mathrm{Ab}$ (human immunodeficiency virus)The patient was treated with $400 \mathrm{mg}$ single-dose, hydroxychloroquine sulfate, lopinavir/ritonavir 100/400mg twice daily for five days, ribavirin $1200 \mathrm{mg}$ twice daily for five days, and three doses of $250 \mu \mathrm{g} \beta$ interferon (Every other day).

During ICU admission, on the third day, fecaloid discharged from abdominal suture appeared, and therefore the patient was on sepsis phase. Laboratory data were CBC (WBC: 24000 per microliter, Hb: 12 g/dL, Plt: 347000 per microliter), urea: 206 $\mathrm{mg} / \mathrm{dL}, \mathrm{Cr}: 3.2 \mathrm{mg} / \mathrm{dL}$, and amylase: $67 \mathrm{U} / \mathrm{L}$.

Re-laparotomy was performed, and after laparotomy, serosanguinous secretions with necrotic changes in the small intestine were seen, so $130 \mathrm{~cm}$ of it was resected (Figure 3). The day after, due to suspicion of leakage from the anastomosis site, laparotomy was performed again and due to leakage from the anastomosis site and smaller bowel necrosis, $100 \mathrm{~cm}$ of intestine was resected so ileostomy was performed. A pathological study (Figures 4) reported intravascular thrombosis in mesenteric tissue with a necrotic margin. The RT-PCR of covid-19 was reported positive.

The patient was treated with heparin infusion and broad-spectrum antibiotics. After 10 days of treatment in ICU, he was extubated, and his hemodynamic was stable, but platelet count began to decrease (162,000 per microliter), and therefore the day after gastrointestinal bleeding happened.

Lab test were CBC (WBC: 7100 per microliter, $\mathrm{Hb}: 8.7 \mathrm{~g} / \mathrm{dL}$, plt: 162000 per microliter), $\mathrm{Cr}: 1.3$ $\mathrm{mg} / \mathrm{dL}$, amylase: $65 \mathrm{U} / \mathrm{L}$. Plt and $\mathrm{Cr}$ decreased to 69000 per microliter and $1.1 \mathrm{mg} / \mathrm{dL}$, respectively, but other coagulation tests (PT and PTT) were normal the day after. Heparin infusion was discontinued. Other laboratory tests were D-dimer: $2500 \mathrm{ng} / \mathrm{mL}$, fibrinogen: $150 \mathrm{mg} / \mathrm{dL}$, PT: $44 \mathrm{sec}$, PTT: $44 \mathrm{sec}$, INR: 1.7. No schistocyte in peripheral blood smear was found. Unfortunately, the patient eventually developed treatment-resistant sepsis, DIC, and died of its complications.

\section{DISCUSSION}

There has been a growing appreciation of the importance of digestive symptoms (nausea, vomiting, anorexia, non-bloody diarrhea, and abdominal pain) within the spectrum of COVID-19 disease. Presumed gastrointestinal manifestations have been reported anywhere from 3\% to $50 \%$ of patients with concomitant SARS-CoV-2 pulmonary infection. ${ }^{10}$ SARS-CoV-2 RNA has been found in fecal samples of patients with COVID-19 pulmonary disease, and initial case series have noted that $3-10 \%$ of patients who are eventually found to have SARS- CoV-2 pulmonary infection were initially presented with isolated digestive symptoms. ${ }^{10}$

However, in some cases, the explanation for the gastrointestinal symptoms could also be important causes, the shortage of specific treatment of which is fatal.For instance, Alexandre Carballo and colleagues presented a case of SARS-CoV-2 gastrointestinal infection causing acute hemorrhagic colitis and signaling COVID-19 disease. ${ }^{11}$

And in this article, we introduced a patient who suffered from intestinal ischemia due to COVID 19 caused by mesenteric vascular thrombosis.

Acute mesenteric ischemia may be a rare disorder defined because of the sudden disruption of the blood 

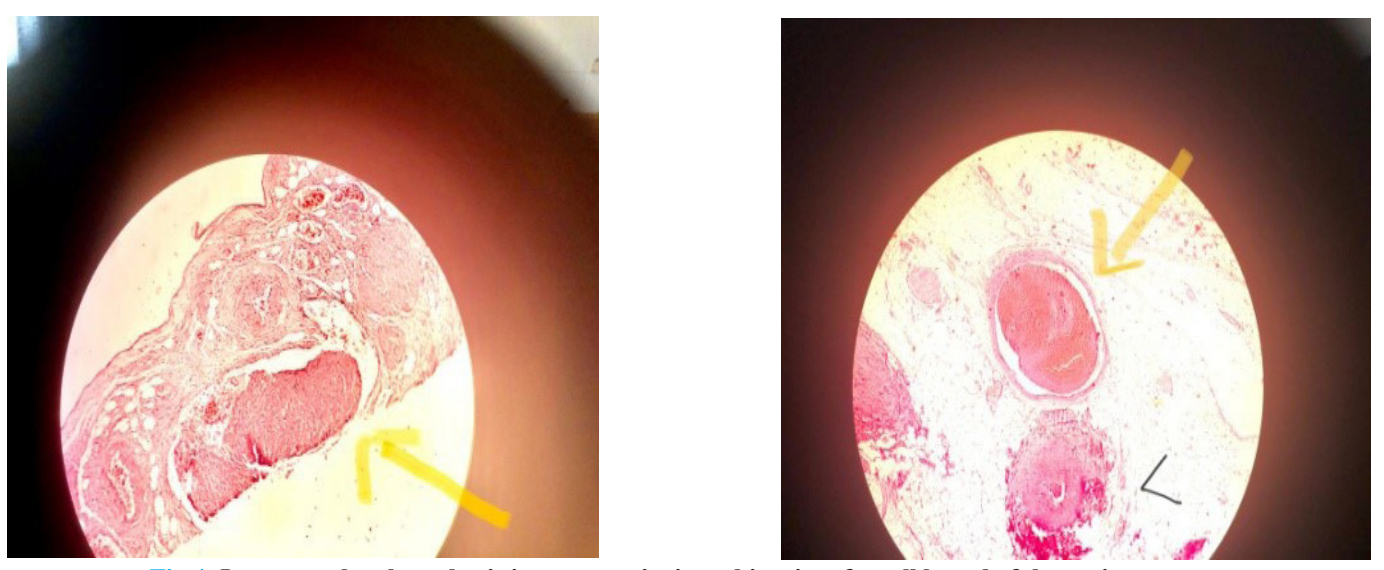

Fig.4: Intravascular thrombosis in mesenteric tissue biopsies of small bowel of the patient

supply to the intestine. ${ }^{12}$ If left untreated, it will cause complications and irreversible consequences like necrosis of the intestinal wall and death. ${ }^{13}$ We distinguished occlusive and non-exclusive types of acute ischemia of the bowel mesentery supported their cause. ${ }^{14}$ Occlusive causes of acute mesenteric ischemia include mesenteric artery embolism (50\% of cases), mesenteric artery thrombosis (15-25\%), and celiac vein thrombosis $(5-15 \%){ }^{15}$

In our opinion, the patient had increased coagulation and mesenteric vascular thrombosis due to COVID-19. There are several reasons why the hypercoagulable state increases in patients with COVID-19 disease. For example, the direct effects of COVID-19 or the indirect effects of infection, like through severe illness and hypoxia, may predispose patients to thrombotic events. Preliminary reports suggest that hemostatic abnormalities, including disseminated intravascular coagulation (DIC), occur in patients suffering from COVID-19. ${ }^{16}$ Additionally, the severe inflammatory response, critical illness, and underlying traditional risk factors may all predispose to thrombotic events, indicate thatcoagulation activation due to infection/sepsis, cytokine storm, and imminent organ failure. Studies have shown higher D-dimer level, fibrin degradation product, and prolonged PT on admission correlated with decreased survival in patients hospitalized for COVID-19 pneumonia, with $71.4 \%$ of patients who died developed overt DIC ${ }^{17}$ and in the $18 \%$ of patients admitted to ICU for COVID-19-associated acute respiratory distress syndrome (ARDS) thrombotic complications were happened.despite anticoagulation therapy, in $16.7 \%$; COVID-19-related to ARDS associated withPE increased thrombotic complications, especially compared to non-
COVID-19-associated ARDS. ${ }^{18}$

However, the important thing is thatCOVID-19 may predispose patients to both venous and arterial thromboembolic disease due to excessive inflammation, hypoxia, immobilization, and disseminated intravascular coagulation (DIC). ${ }^{19}$

Patients with COVID 19 are reported to have vascular events; for example, Avila and co-workers reported four patients presenting with imaging that confirmed acute strokes and PCR results that confirmed SARS-CoV-2 infection. ${ }^{20}$

Coagulopathy, antiphospholipid antibodies, and multiple cerebral infarctions were detected in two men (69 and 70 years old) and one woman (65 years old) admitted to ICU for COVID-19 in a case series. ${ }^{21}$ Our patient had mesenteric vascular thrombosis and suffered from small bowel ischemia. In our review, this is the first report of this demonstration.

\section{CONCLUSION}

Abdominal pain is seen in some patients with COVID-19 and is mostly diagnosed as a gastrointestinal manifestation of this infection, but the important point is that the cause of this abdominal pain may be other important reasons, and the delay in specific treatment is fatal.

\section{ACKNOWLEDGMENTS}

We hereby thank dear professors and colleagues of the Clinical Research Development Unit of Shahid Behest Hospital who helped researchers. 


\section{ETHICAL APPROVAL}

There is nothing to be declared.

\section{CONFLICT OF INTEREST}

The authors declare no conflict of interest related to this work.

\section{REFERENCES}

1. WHO. Coronavirus Disease (COVID-2019) situation reports. 2020.https://www.who.int/emergencies/diseases/novel-coronavirus-2019/situation reports. Accessed 5 Mar 2020

2. Adeli SH, Asghari A, Tabarraii R, Shajari R, Afshari $\mathrm{S}$, Kalhor N, et al.Using therapeutic plasma exchange as rescue therapy in CoVID-19 patients: a case series. Pol Arch Intern Med 2020;13:455-8. doi: 10.20452/ pamw.15340. Epub 2020 May 7.

3. Wu Z, McGoogan JM. Characteristics of and Important Lessons From the Coronavirus Disease 2019 (COVID-19) Outbreak in China: Summary of a Report of 72314 Cases From the Chinese Center for Disease Control and Prevention. JAMA 2020;323:1239-42. doi:10.1001/jama.2020.2648

4. Thachil J, Tang N, Gando S, Falanga A, Cattaneo M, Levi M,et al. ISTH interim guidance on recognition and management of coagulopathy in COVID-19. J Thromb Haemost 2020;18:1023-6. doi: 10.1111/jth.14810.

5. Richardson S, Hirsch JS, Narasimhan M, Crawford JM, McGinn T, Davidson KW, et al. Presenting Characteristics, Comorbidities, and Outcomes Among 5700 Patients Hospitalized With COVID-19 in the New York City Area. JAMA 2020;323:2052-9. doi:10.1001/jama.2020.6775.

6. Middeldorp S, Coppens M, Haaps TF, Foppen M,Vlaar AP, Müller MCA, et al.Incidence of venous thromboembolism in hospitalized patients with COVID-19. J Thromb Haemos 2020;18:1995-2002.doi: 10.1111/ jth.14888.

7. Tang N, Bai H, Chen X, Gong J, Li D, Sun Z. Anticoagulant treatment is associated with decreased mortality in severe coronavirus disease 2019 patients with coagulopathy. J Thromb Haemost 2020;18:1094-9. doi: $10.1111 /$ jth.14817.

8. Lillicrap D. Disseminated intravascular coagulation in patients with 2019-nCoV pneumonia. $J$ Thromb Haemost 2020;18:786-7. doi: 10.1111/jth.14781.

9. Panigada M, Bottino N, Tagliabue P, Grasselli G, Novembrin C, Chantarangkul V, et al. Hypercoagulability of COVID-19 patients in the Intensive Care Unit. A Report of Thromboelastography Findings and other Parameters of Hemostasis. J Thromb Haemost 2020;18:1738-42. doi: 10.1111/jth.14850.

10. Pan $\mathrm{L}, \mathrm{Mu} \mathrm{M}$, Yang $\mathrm{P}$, Sun Y,Wang R, Yan J, et al. Clinical Characteristics of COVID-19 patients with digestive symptoms in Hubei, China: A descriptive, cross-sectional, multicenter study. Am $J$ Gastroenterol 2020;115:766-73. doi:10.14309/ ajg.0000000000000620.

11. Carvalho A, Alqusairi R, Adams A, PaulM, Kothari $\mathrm{N}$, Peters S, et al. SARS-CoV-2 Gastrointestinal Infection Causing Hemorrhagic Colitis: Implications for Detection and Transmission of COVID-19 Disease. Am J Gastroenterol 2020;115:942-6.doi: 10.14309/ ajg.0000000000000667.

12. Stone JR, Wilkins LR. Acute mesenteric ischemia. Tech Vasc Interv Radiol 2015;18:24-30.doi: 10.1053/j. tvir.2014.12.004.

13. Clair D, Beach JM. Mesenteric Ischemia. NEngl J Med 2016;374:959-68. doi:10.1056/NEJMra1503884.

14. Jagielski M, Piątkowski J, Jackowski M. Challenges Encountered during the Treatment of Acute Mesenteric Ischemia. Gastroenterol Res Pract 2020;2020:5316849. doi: 10.1155/2020/5316849. eCollection 2020.

15. Acosta S. Mesenteric ischemia. Curr Opin Crit Care 2015;21:171-8. doi: 10.1097/MCC.0000000000000189.

16. Tang N, Li D, Wang X, Sun Z. Abnormal coagulation parameters are associated with poor prognosis in patients with novel coronavirus pneumonia. J Thromb Haemost 2020;18:844-7. doi: 10.1111/jth.14768.

17. David Lillicrap. Disseminated intravascular coagulation in patients with 2019-nCoV pneumonia. J Thromb Haemost 2020;18:786-7. doi: 10.1111/jth.14781.

18. Helms J, Jacquard C, Severac F, Leonard-Lorant I, Ohana M, Delabranche X, et al. High risk of thrombosis in patients with severe SARS-CoV-2 infection: a multicenter prospective cohort study. Intensive Care Med 2020;46:1089-98. doi: 10.1007/s00134-020-06062-x.

19. Klok FA, Kruip MJHA, van der Meer NJM, Arbous MS, Gommers DAMPJ, Kant KM, et al. Incidence of thrombotic complications in critically ill ICU patients with COVID-19. Thromb Res 2020;191:145-7. doi: 10.1016/j.thromres.2020.04.013.

20. Avula A, Nalleballe K, Narula N,Sapozhnikov S, Dandu $\mathrm{V}$, Toom S, et al. COVID-19 presenting as strok. Brain Behav Immun 2020;87:115-9. doi: 10.1016/j. bbi.2020.04.077.

21. Zhang Y, Xiao M, Zhang S, Xia P, Cao W, Jiang W, et al. Coagulopathy and Antiphospholipid Antibodies in Patients with Covid-19. N Engl J Med 2020;382:e38. doi: 10.1056/NEJMc2007575. 